Published in final edited form as:

J Phys Chem A. 2003 October 30; 107(43): 9175-9181.

\title{
Quantifying the Role of Water in Protein-Carbohydrate Interactions
}

\author{
Sarah M. Tschampel and Robert J. Woods* \\ Complex Carbohydrate Research Center, University of Georgia, 220 Riverbend Road, Athens, \\ Georgia 30602
}

\section{Abstract}

Water-mediated interactions play a key role in carbohydrate-lectin binding, where the interactions involve a conserved water that is separated from the bulk solvent and present a bridge between the side chains of the protein and the carbohydrate ligand. To apply quantum mechanical methods to examine the role of conserved waters, we present an analysis in which the relevant carbohydrate atoms are modeled by methanol, and in which the protein is replaced by a limited number of amino acid side chains. Clusters containing a conserved water and a representative amino acid fragment were also examined to determine the influence of amino acid side chains on interaction energies. To quantify the differential binding energies of methanol versus water, quantum mechanical calculations were performed at the B3LYP/6-311++G(3df,3pd)//B3LYP/6-31+G(d) level in which either a methanol molecule was bound to the conserved water (liganded state) or in which a water molecule replaces the methanol (unliganded state). Not surprisingly, the binding of a water to clusters containing charged amino acid side chains was more favorable by 1.55 to $7.23 \mathrm{kcal} / \mathrm{mol}$ than that for the binding of a water to the corresponding pure water clusters. In contrast, the binding energy of water to clusters containing polar-uncharged amino acid side chains ranged from $4.35 \mathrm{kcal} / \mathrm{mol}$ less favorable to $4.72 \mathrm{kcal} / \mathrm{mol}$ more favorable than for binding to the analogous pure water clusters. The overall trend for the binding of methanol versus water, in any of the clusters, favored methanol by an average value of $1.05 \mathrm{kcal} / \mathrm{mol}$. To extend these studies to a complex between a protein (Concanavalin A) and its carbohydrate ligand, a cluster was examined that contained the side chains of three key amino acids, namely asparagine, aspartate, and arginine, as well as a key water molecule, arranged as in the X-ray diffraction structure of Con A. Again, using methanol as a model for the endogenous carbohydrate ligand, energies of $-5.94 \mathrm{kcal} / \mathrm{mol}$ and $-5.70 \mathrm{kcal} / \mathrm{mol}$ were obtained for the binding of methanol and water, respectively, to the Con A-water cluster. The extent to which cooperativity enhanced the binding energies has been quantified in terms of nonadditive three-body contributions. In general, the binding of water or methanol to neutral dimers formed cooperative clusters; in contrast, the cooperativity in charged clusters depended on the overall geometry as well as the charge.

\section{Introduction}

Water plays a ubiquitous role in stabilizing biomolecular structure and facilitating biological function. In both proteins and protein-ligand complexes, water molecules may occupy specific positions on the protein surface, and moreover, water molecules have been found in ligandbinding sites, bridging the interaction between the protein and the ligand. ${ }^{1-3}$ The presence of conserved water molecules is not unique to proteins, but has also been observed in RNA, in which a water molecule can mediate the hydrogen-bonding interactions between two base

\footnotetext{
* Corresponding author. Phone: 706-542-4454. Fax: 706-542-4412. E-mail: rwoods@ccrc.uga.edu..

Supporting Information Available: Calculations for both the binding energy and three-body contributions for all complexes investigated. This material is available free of charge via the Internet at http://pubs.acs.org.
} 
pairs. ${ }^{4}$ Water-mediated ligand binding is a common feature in X-ray structures of carbohydrate-lectin complexes, including the well-studied Concanavalin A (Con A)trimannoside system. 5,6 The focal point of this study is to determine the extent to which the properties of water in protein-(conserved water) complexes differ from those in pure water clusters, and to assess the extent to which these differences may contribute to ligand affinity.

Considerable experimental and theoretical data are available pertaining to the quantification of intermolecular interactions in water. ${ }^{7-18}$ The focus of a substantial portion of this research has been the water dimer, which, because of its size, has facilitated treatment with high-level $a b$ initio methods. ${ }^{17}$ One of the most well-studied heterodimers is the methanol-water system, which has a theoretical binding energy of $-5.9 \mathrm{kcal} / \mathrm{mol}$ at the complete basis set (CBS) limit at the level of second-order Møller Plesset (MP2) pertubation theory, ${ }^{19}$ which may be compared to $-5.0 \mathrm{kcal} / \mathrm{mol}$ for the water dimer at the CBS limit of the coupled-cluster level with single and double substitutions, with triple excitations included perturbatively (CCSD (T)). ${ }^{20}$ The binding energy is enhanced upon formation of the corresponding trimers, from the three individual monomers, to $-10.8 \mathrm{kcal} / \mathrm{mol}$ at the MP4 level for the water trimer and -11.5 $\mathrm{kcal} / \mathrm{mol}$ at the Gaussian-2 (G2)(MP2) level for the $\left(\mathrm{H}_{2} \mathrm{O}\right)_{2}-\mathrm{CH}_{3} \mathrm{OH}$ trimer. ${ }^{21,22}$ More recent computations for the water trimer yield a binding energy of $-15.8 \mathrm{kcal} / \mathrm{mol}$ at the CBS limit of MP4 theory. 23

Studies of the water trimer by Xantheas et al. revealed that the total two-body interaction energy is $-11.57 \mathrm{kcal} / \mathrm{mol}$, in which $-2.40 \mathrm{kcal} / \mathrm{mol}$ results from three-body (cooperative) interactions. 24 Notably, the magnitude of the three-body interaction depended on the orientation of the monomers in the trimer. A similar study on water-mediated base-pairing in RNA revealed that 9-13\% of the interaction energy was due to cooperativity (at both the MP2 and HF levels of theory). ${ }^{4}$ In this work, we report the effect of cooperativity on a variety of small biologically relevant clusters, employing the analysis utilized by Xantheas 24 to quantify the contribution from cooperativity. The dimers investigated here each contain one water molecule, as well as a representative fragment of one of the following side chains: asparagine or glutamine, arginine, aspartate or glutamate, lysine, threonine or serine, and tyrosine. While this study does not present an exhaustive analysis of all possible configurations, each structure has been shown to be a minimum on the potential energy surface.

It has been established that MP2 theory gives reasonable results for energies and geometries of hydrogen-bonded complexes. ${ }^{25}$ However, to extend this study to larger complexes, density functional theory was chosen over the more time-consuming MP2 computations. Calculations employing the B3LYP functional have been shown to yield good agreement with MP2 geometries and structures for hydrogen-bonded complexes, including water clusters. ${ }^{26,27}$ Geometries of neutral $\mathrm{N}-\mathrm{H} \cdots \mathrm{O}$ hydrogen-bonded complexes, also computed with the B3LYP functional, have been shown to agree with experimental data. ${ }^{28}$ In addition, agreement with experiment for density functional theory is well established for strongly bound ionic complexes, involving either negatively or positively charged ions, such as the $\mathrm{OH}^{-}\left(\mathrm{H}_{2} \mathrm{O}\right)$ and the $\mathrm{H}_{3} \mathrm{O}^{+}\left(\mathrm{H}_{2} \mathrm{O}\right)$ complexes. ${ }^{29,30}$ Overall, it has been determined that diffuse functions must be included in order to determine accurate binding energies and structures for hydrogen-bonded complexes when utilizing this methodology. 25,31

Con A is a widely studied carbohydrate-binding protein (lectin) and has been used frequently as a model to study carbohydrate-protein complexation due to its affinity for oligosaccharides terminating in glucopyranosyl residues. ${ }^{32} \mathrm{X}$-ray diffraction data are available for several Con A-carbohydrate complexes, including those with methyl $\alpha$-D-glucopyranoside, ${ }^{33}$ methyl $\alpha$-Dmannopyranoside, ${ }^{34}$ and a methyl 3,6-di- $O$-( $\alpha$-D-mannopyranosyl)- $\alpha$-D-mannopyranoside (trimannoside). ${ }^{6}$ In all three complexes, water-mediated hydrogen-bond networks are formed. $1,6,33,34$ In the Con A-trimannoside complex, a conserved water interacts with three key 
amino acids, namely, asparagine, arginine, and aspartate. In this study, a single methanol molecule is used to provide a minimal approximation of the carbohydrate ligand. 1,6

Desolvation entropy will not be accounted for in this study although it is known to play a significant role in carbohydrate binding to Con A. ${ }^{1,35-38}$ The structure of bulk water is known to become more ordered when around methanol relative to that of water, which results in a favorable desolvation entropy in the case of methanol, relative to water. ${ }^{39}$ For each cluster, the entropic contribution of methanol will be assumed to be consistently greater in all cases, relative to water, resulting in a more favorable free energy by enhancing the calculated enthalpic differences. Furthermore, variation in enthalpies for the binding of different carbohydrate ligands to Con A correlates directly with the number of hydrogen bonds formed. 1,37 Therefore, by conserving the number of hydrogen bonds in the formation of either water or methanol complexes, the enthalpic contribution will reflect the influence of the ligand rather than the number of hydrogen bonds formed.

\section{Methods}

All structures were optimized at the B3LYP level of theory 40,41 with a $6-31+G(d)$ basis set utilizing the Gaussian 98 suite of programs. ${ }^{42}$ For all species under investigation, frequency analyses were performed at the same level of theory to ensure all structures were minima and to determine the zero-point vibrational energies (ZPVEs). The ZPVEs were subsequently scaled by an empirical factor of 0.9775 .43 In addition, single-point energy calculations were performed with the $6-311++\mathrm{G}(3 \mathrm{df}, 3 \mathrm{pd})$ basis set.

All systems may be described by the same binding reaction, in which either methanol or water binds to a preexisting dimer as shown in eq 1 :

$$
\mathrm{AA}-\mathrm{H}_{2} \mathrm{O}+\mathrm{HOR} \rightarrow \mathrm{AA}-\mathrm{H}_{2} \mathrm{O}-\mathrm{HOR}\left(\mathrm{R}=\mathrm{H}, \mathrm{CH}_{3}\right)
$$

The completely corrected value for the binding energy was obtained by summing the energy calculated from the Boys-Bernardi scheme, ${ }^{44}$ the relaxation correction, ${ }^{4,45}$ and the ZPVE correction. This is the value referred to in the text unless otherwise noted. Because of the large structural changes observed between the isolated monomer and that in the cluster geometry, it was necessary to compute the relaxation energies. ${ }^{45}$ Three-body interaction terms were determined utilizing the method of Xantheas. 46

The following nomenclature was adopted throughout the rest of the text. The one-letter amino acid abbreviations are used to represent the AA-water dimers. In the case that there is a second, less stable dimer it is indicated by a prime. Inclusion of a superscript $\mathrm{C}$ represents a cyclic motif, while a superscript $\mathrm{L}$ a linear motif. In the cyclic complexes the binding moiety is specified with a superscript a, b, or c. For example, the notation to illustrate the linear trimer formed by the binding of $\mathrm{HOR}\left(\mathrm{R}=\mathrm{CH}_{3}\right)$ to the tyrosine $-\mathrm{H}_{2} \mathrm{O}$ dimer will be abbreviated as $\mathbf{Y}^{\mathbf{L}} \mathbf{R = \mathbf { C H } _ { 3 }}$. In general, the hydrogen bonding distances are defined as the distance from the oxygen acceptor to the donating hydrogen unless otherwise stated.

In the case of $\mathbf{Y}^{\mathbf{L}}$, the expected linear cluster where tyrosine acted as a hydrogen-bond donor collapsed to the cyclic cluster. Therefore, the binding energy is calculated with respect to the dimer, which is in the same hydrogen-bonding arrangement, $\mathbf{Y}^{\prime}$. Additionally, five more of the neutral clusters, $\mathbf{N}_{\mathbf{R a}} \mathbf{C}_{\mathbf{R}}, \mathbf{N}_{\mathbf{R b}}, \mathbf{N}^{\mathbf{L}}, \mathbf{Y}_{\mathbf{R b}} \mathbf{C}_{\text {, and }} \mathbf{T}_{\mathbf{R b}}^{\mathbf{C}_{\mathbf{R}}}$ were calculated with respect to, $\mathbf{N}^{\prime}, \mathbf{N}^{\prime \prime}$, $\mathbf{N}^{\prime \prime}, \mathbf{Y}^{\prime}$, and $\mathbf{T}^{\prime}$, respectively, to be consistent with the hydrogen-bonding arrangement. In the cyclic complexes more than just the lowest energy complex was analyzed to provide an overview of the different hydrogen-bond arrangements as well as the small barrier between the possible complexes. 
The Cartesian coordinates for the Con A-trimannoside complex were retrieved from the RCSB Protein Database (1CVN.pdb). ${ }^{6}$ Hydrogen atoms were added to the X-ray coordinates using the Builder Module of InsightII. The protein complex was simplified to contain only the truncated amino acids and the trimannoside ligand that participate in the hydrogen-bonding interactions at the binding site. Two copies were made of the simplified complex. In the first copy, the trimannoside ligand was replaced by methanol, aligned with the carbon atom (C2) and the hydroxyl group (HO-2) of the central mannosyl residue. Hydroxyl group HO-2 is involved in hydrogen-bonding interactions with the protein, via a conserved water molecule. In the second copy, the trimannoside ligand was replaced by a water molecule, which was formed from hydroxyl group HO-2. Initially, the non-hydrogen atoms of the amino acids as well as the conserved water were frozen during geometry optimization in order to maintain the configuration present in the crystal structure while allowing the hydrogen positions to relax. An additional optimization allowed the whole complex to be fully optimized in order to determine the effects of ZPVE.

\section{Results and Discussion}

\section{Water Clusters}

At the B3LYP/6-31+G(d) level the average internuclear O … distance was $2.77 \AA$ in the water trimer, which compared favorably with theoretical results obtained at the MP2//aug-cc-pVDZ level $(2.80 \AA),{ }^{13,16}$ although both values underestimate the experimental value of $2.85 \AA .8$ When methanol was substituted for one water in the water trimer, the hydrogen bond formed between methanol, acting as an acceptor, and the neighboring water decreased in length by $0.02 \AA$ relative to that in the water trimer. In contrast, when methanol acted as a donor, the hydrogen-bond distance increased by the same amount, relative to the corresponding hydrogen bond in the water trimer. These results agree with previous studies that showed that the strongest hydrogen bond in the $\left(\mathrm{H}_{2} \mathrm{O}\right)_{2}-\mathrm{CH}_{3} \mathrm{OH}$ trimer occurs when methanol acts as an acceptor, whereas in the weakest methanol acts as a donor. 21

The binding energy for the water trimer from the water dimer and the water monomer was $-5.96 \mathrm{kcal} / \mathrm{mol}$. Upon substitution of a single water monomer for methanol, three different $\left(\mathrm{H}_{2} \mathrm{O}\right)_{2}-\mathrm{CH}_{3} \mathrm{OH}$ trimers are formed, the a-, b-, and c-complexes shown in Figure 1. The average binding energy of methanol to the water dimer was more favorable than water with a value of $-6.82 \mathrm{kcal} / \mathrm{mol}$, shown in Table 1 . This difference in energy is in agreement with previous theoretical results that showed the dissociation energy to be about $1 \mathrm{kcal} / \mathrm{mol}$ more negative for $\left(\mathrm{H}_{2} \mathrm{O}\right)_{2}-\mathrm{CH}_{3} \mathrm{OH}$ than for $\left(\mathrm{H}_{2} \mathrm{O}\right)_{3} \cdot 21$

The cooperativity terms are favorable for the binding of methanol, or water, to the water dimer. The cooperativity term was $-2.94 \mathrm{kcal} / \mathrm{mol}$ for the water trimer, which is in agreement with previous calculations at the MP2/aug-cc-pVTZ level that yielded $-2.45 \mathrm{kcal} / \mathrm{mol} .{ }^{24}$ In contrast, when methanol bound to the dimer the magnitude of the cooperativity term depended on which of the three complexes was formed. The largest enhancement $(-3.37 \mathrm{kcal} / \mathrm{mol})$ was seen in the a-trimer, whereas the enhancement in the b- and c-trimers was approximately $-2.88 \mathrm{kcal} / \mathrm{mol}$. This was expected because the methyl group in the a-trimer projected into the plane opposite to both of the water protons that were not participating in the hydrogen-bonding interactions, thus avoiding any possible unfavorable stereoelectronic interactions. Previous calculations of the three-body interaction energy for the a-trimer, at the G2(MP2) and B3LYP/6-311+G(3df, $2 \mathrm{p}$ ) levels, yielded -3.0 and $-2.9 \mathrm{kcal} / \mathrm{mol}$, respectively. 21

\section{Uncharged Clusters}

For each of the three uncharged dimers, more than one local minima was determined to be consistent with the hydrogen-bonding networks of the larger clusters. The differences in the 
cluster geometries of both the tyrosine (Y) and threonine (T) dimers were based on the ability of the hydroxyl groups in these amino acid side chains to act as either donor or acceptor atoms in hydrogen-bond formation. The threonine side chain preferred to be an acceptor, by 0.94 $\mathrm{kcal} / \mathrm{mol}$, while the tyrosine side chain preferred to be a donor, by $2.15 \mathrm{kcal} / \mathrm{mol}$, which is expected on the basis of the lower $\mathrm{p} K_{\mathrm{a}}$ of the phenolic proton (Table 2 ). In both cases, the hydrogen-bond distances were shorter in the more energetically favored structures, although the $\mathrm{O}-\mathrm{H} \cdots \mathrm{O}$ angles were also slightly more distorted from linearity, to values of $172.40^{\circ}$ and $170.26^{\circ}$ for $\mathbf{Y}$ and $\mathbf{T}$, respectively.

Within all four linear trimers, $\mathbf{Y}, \mathbf{N}^{\mathbf{L}}, \mathbf{N}^{\mathbf{L}}$, and $\mathbf{T}^{\mathbf{L}}$, similar structural trends were observed, and are shown in Figure 2. For example, upon substituting methanol for water, the AA-(conserved water) hydrogen bond typically did not change in length significantly, with only a slight decrease in the methanol-water hydrogen bond length relative to that of water-water, of approximately $0.02 \AA$, and an average deviation of $1.23^{\circ}$ in the $\mathrm{O}-\mathrm{H} \cdots \mathrm{O}_{\mathrm{meoh}} /$ water angle. This modest geometrical difference is consistent with the $0.69 \mathrm{kcal} / \mathrm{mol}$ favorable increase in binding energy when methanol is the ligand, relative to water. The uncharged cyclic trimers $\left(\mathbf{Y}^{\mathbf{C}}, \mathbf{N}^{\mathbf{C}}\right.$, and $\left.\mathbf{T}^{\mathbf{C}}\right)$ behaved similarly to the $\left(\mathrm{H}_{2} \mathrm{O}\right)_{2}-\mathrm{CH}_{3} \mathrm{OH}$ trimers. For example, when the ligand acted as an acceptor, the binding of methanol resulted in a stronger hydrogen bond, relative to the binding of water. In contrast, when the ligand acted as a donor, the hydrogen bond was stronger for water than for methanol.

Complexation of either methanol or water to the uncharged amino acid-water clusters resulted in binding energies that ranged from -11.59 to $-1.61 \mathrm{kcal} / \mathrm{mol}$. The same energetic trend is not seen in both cyclic and linear clusters due to the presence of separate atoms acting as the donor and the acceptor in the cyclic asparagine complex, which is a more favorable interaction than the same atom acting as both the donor and acceptor as in tyrosine and threonine.

Formation of neutral cyclic clusters is more favorable than for the corresponding neutral linear cluster. Inclusion of the relaxation energy, which is generally larger for the cyclic clusters due to the inherently strained geometry in the cyclic clusters, decreased the separation between the two types. The three clusters, $\mathbf{Y}_{\mathbf{R b}} \mathbf{C}_{\mathbf{R}} \mathbf{T}_{\mathbf{R b}}$, and $\mathbf{N}^{\mathbf{L}}$, were higher in energy than $\mathbf{Y}_{\mathbf{R a}} \mathbf{C}_{\text {, }}$ $\mathbf{T}^{\mathbf{C}}{ }_{\mathbf{R a}}$, and $\mathbf{N}^{\mathbf{L}}$, respectively (Table 3), due to the less favorable hydrogen-bonding network present. As a result, the dimer utilized in the binding energy calculations is consistent with the hydrogen bond network present in the trimer, but is not the lowest energy structure. In all cases this results in a more favorable binding energy relative to that of the corresponding calculation utilizing the lowest energy dimer.

Overall, neutral clusters exhibited favorable three-body interaction energies, except for the case of $\mathbf{N}^{\mathbf{L}}$. $\mathbf{N}^{\mathbf{L}}$ is unique from all other neutral clusters because the conserved water acts as both a donor to the carbonyl oxygen and an acceptor for the amide group of the asparagine side chain. Addition of a second water increases the length of the hydrogen bond with the carbonyl group and slightly decreases the length of the hydrogen bond involving the amide group. Since the three-body term is unfavorable, the weakening of the carbonyl-(conserved water) hydrogen bond dominates the energy.

\section{Charged Clusters}

For the three charged clusters investigated here, only one energy minimum was found for each dimer. The aspartate- $\mathrm{H}_{2} \mathrm{O}$ and lysine- $\mathrm{H}_{2} \mathrm{O}$ dimers each had one distinct structure, $\mathbf{D}$ and $\mathbf{K}$, respectively, while the arginine- $\mathrm{H}_{2} \mathrm{O}$ dimer had the possibility of a second structure containing only one of the two hydrogen bonds that are present in structure $\mathbf{R}$ (Figure 3 ). At the level of theory utilized here, this second putative structure collapsed to $\mathbf{R}$, which agrees with previous studies of related systems where the minimum structure contained two hydrogen bonds. 47 Linear and cyclic structures were found to be minima for the arginine- $\left(\mathrm{H}_{2} \mathrm{O}\right)_{2}$ cluster, while 
the linear structure for aspartate- $\left(\mathrm{H}_{2} \mathrm{O}\right)_{2}$ collapsed to the cyclic DC cluster during geometry optimization.

The $\mathbf{K}^{\mathbf{B}}$ cluster was unique in that both waters were bound directly to the amino acid side chain without a water-water hydrogen bond. In this branched structure both of the $\mathrm{N}-\mathrm{H} \cdots \mathrm{O}$ angles remained close to linearity (see Figure 3). ${ }^{48}$ In both of the lysine- $\left(\mathrm{H}_{2} \mathrm{O}\right)-\left(\mathrm{CH}_{3} \mathrm{OH}\right)$ clusters, as well in the linear arginine- $\left(\mathrm{H}_{2} \mathrm{O}\right)-\left(\mathrm{CH}_{3} \mathrm{OH}\right)$ cluster, the hydrogen bond that directly involved methanol was stronger than the corresponding interaction found in the lysine$\left(\mathrm{H}_{2} \mathrm{O}\right)_{2}$ cluster, revealing a more favorable interaction with methanol.

Both aspartate and arginine formed true cyclic structures, which are comparable geometrically to the water trimer. Upon formation of $\mathbf{D}^{\mathbf{C}}$ and $\mathbf{R}^{\mathbf{C}}$, the average hydrogen-bond lengths decreased relative to those in the isolated dimers. This was mostly due to the strained configuration of the dimers, in which water acted as either a double acceptor or a double donor. In both structures, the shortest hydrogen bond corresponded to the one involving an $\mathrm{N}-\mathrm{H} \cdots \mathrm{O}$ or $\mathrm{O}-\mathrm{H} \cdots \mathrm{O}$ angle that remained close to linearity. The hydrogen-bond distances in both cyclic structures were similar to those in the water trimer. Small fluctuations in hydrogen-bond lengths of less than $0.05 \AA$ were observed upon the replacement of water by methanol. In contrast to the neutral clusters, the hydrogen bond was not always stronger when methanol was acting as an acceptor. For example, in $\mathbf{D}^{\mathbf{C}}$, the strongest hydrogen bond existed when methanol donated to the aspartate.

The binding energies of water to each of the charged AA- $\mathrm{H}_{2} \mathrm{O}$ dimers ranged from 1.55 to $7.23 \mathrm{kcal} / \mathrm{mol}$ more favorable than the binding energy of water to $\left(\mathrm{H}_{2} \mathrm{O}\right)_{2}$. According to the binding energies, the strength of the water interactions with the complexes may be ranked from weakest to strongest as $\mathbf{R}_{\mathbf{R b}}^{\mathbf{C}_{\mathbf{b}}}>\mathbf{R}^{\mathbf{C}_{\mathbf{R a}}} \mathbf{R}^{\mathbf{L}}>\mathbf{K}^{\mathbf{L}}>\mathbf{D}^{\mathbf{C}}>\mathbf{K}^{\mathbf{B}}$. The formation of the two cyclic arginine clusters relied on the breaking of one of the hydrogen bonds in the dimer, to form two new hydrogen bonds in the trimer. This bond breaking may have contributed to the $2.08 \mathrm{kcal} /$ mol destabilization of the complex relative to the linear arginine cluster. The binding energy of water to either the lysine or aspartate clusters was at least $1.5 \mathrm{kcal} / \mathrm{mol}$ more favorable than that to the arginine cluster. This may possibly be due to the more localized charge in the lysine and aspartate clusters, relative to the case of arginine. Further, the more favorable binding of water to $\mathbf{D}^{\mathbf{C}}$ relative to $\mathbf{R}^{\mathbf{L}}$ is consistent with the observation that water prefers to act as a bidonor rather than a bi-acceptor. ${ }^{22}$ Theoretical measurements and experimental calculations have shown that for the related structures of $\left(\mathrm{H}_{2} \mathrm{O}\right)_{2} \mathrm{OH}^{-}$and $\left(\mathrm{H}_{2} \mathrm{O}\right)_{2} \mathrm{H}_{3} \mathrm{O}^{+}$the formation of the positively charged cluster is more favorable, which agrees with our findings that the formation of the cyclic lysine cluster was more favorable than that of the cyclic aspartate cluster. 49,50

The binding energy of the branched lysine cluster $(-13.2 \mathrm{kcal} / \mathrm{mol})$ was more favorable than that for the linear cluster $(-11.1 \mathrm{kcal} / \mathrm{mol})$, which is also in agreement with previous calculations that revealed the branched structure to be $2.5 \mathrm{kcal} / \mathrm{mol}$ more stable than the linear structure. ${ }^{48}$ The conserved water was in approximately the same position in both lysine trimers. Therefore, the majority of the difference in binding energy is related to the interactions involving the bound water. In the branched structure the bound water directly interacted with the charged entity, helping to stabilize the complex, while the bound water in the linear structure was not involved in direct interactions with the ammonium group.

The binding energies of methanol to each of the charged AA- $\mathrm{H}_{2} \mathrm{O}$ dimers were from 1.92 to $8.23 \mathrm{kcal} / \mathrm{mol}$ more favorable than the binding of methanol to the water dimer. The binding energies followed the same trend regardless of whether the ligand was methanol or water, however the differences in binding energies were more substantial in the case of methanol. Overall, the average binding energy of methanol to the charged clusters was $1.58 \mathrm{kcal} / \mathrm{mol}$ 
more favorable than that of water, which represents a favorable increase of $0.78 \mathrm{kcal} / \mathrm{mol}$ from the uncharged clusters.

The magnitude of the cooperative effects varied significantly among the charged clusters. For example, both $\mathbf{K}^{\mathbf{L}}$ and $\mathbf{K}^{\mathbf{B}}$ contain the lysine side chain, but had three-body terms that were opposite in sign. Only in the case of the linear charged clusters was cooperativity consistently favorable. In the cases of $\mathbf{K}^{\mathbf{B}}, \mathbf{R}^{\mathbf{C}}$, and $\mathbf{D}^{\mathbf{C}}$, the addition of the ligand to form the cyclic or branched structures involved a direct interaction between the ligand and the amino acid side chains. Although this helped to stabilize the charged side chains, the (conserved-water)-AA hydrogen bond was weakened, resulting in unfavorable cooperativity. In contrast, when the ligand bound to form the linear clusters $\mathbf{K}^{\mathbf{L}}$ and $\mathbf{R}^{\mathbf{L}}$, the ligand interacted only with the conserved water and as a result, the conserved water was polarized and the (conserved-water)ligand hydrogen bond was strengthened. This configuration resulted in favorable cooperativity. In general, the charged linear clusters exhibited more cooperativity than the charged cyclic clusters, which is in contrast to the results for the uncharged clusters.

\section{Protein-Carbohydrate Interactions}

Due to the absence of the hydrogen atoms in the X-ray diffraction data, donor-acceptor hydrogen-bond relationships had to be inferred. By assuming that arginine-228 and asparagine-14 residues must be donor groups and that aspartate-16 provides the acceptor group, it was possible to locate the approximate positions of all hydrogen atoms. The geometry of the fully optimized Con $\mathrm{A}-$ (conserved water) $-\mathrm{CH}_{3} \mathrm{OH}$ complex did not differ significantly from that of the Con A-(conserved water) $-\mathrm{H}_{2} \mathrm{O}$ complex, with a RMSD of $0.27 \AA$ for the heavy atoms, see Figure 4. The RMSD between the crystal structure and the Con A-(conserved water) $-\mathrm{H}_{2} \mathrm{O}$ complex was $0.63 \AA$, while that with the Con $\mathrm{A}-($ conserved water $)-\mathrm{CH}_{3} \mathrm{OH}$ complex was $0.65 \AA$.

The interactions between the aspartate side chain and both the conserved and bound water in the Con A complex is similar to $\mathbf{D}^{\mathbf{C}}$; however, in the Con A complex the conserved water is further coordinated to other side chains. These additional interactions decrease the strength of the hydrogen bond between the aspartate side chain and the ligand, while increasing the strength of the two hydrogen bonds involving the conserved water. The result is a conserved water that is more polarized, yielding a more favorable configuration in the Con A complex. Comparison of the asparagine side chain in the Con A complex to that in $\mathbf{N}^{\mathbf{L}}$ reveals no significant differences. The arginine side chain in the Con A complex is in a less favorable configuration than in $\mathbf{R}^{\mathbf{L}}$ due to the presence of only one hydrogen bond in the Con A complex relative to two in $\mathbf{R}^{\mathbf{L}}$. Therefore, the presence of additional side chains makes a larger impact on the geometries of the charged residues than on the neutral residues.

Initially, the Con A complex was partially optimized, while holding the heavy atoms of the side chains and the conserved water in their crystallographically determined positions to determine a biochemically relevant binding energy. In analogy with the smaller clusters, one would expect the hydrogen bonds in the Con A system to strengthen upon the binding of methanol, in comparison to the binding of water. However, the hydrogen-bond distances for both methanol and water were equivalent. There was only a negligible difference of $0.02 \mathrm{kcal} /$ mol in the binding energy of methanol to the Con A cluster, relative to the case of water, for the partially optimized complex corresponding to the lack of difference in the geometry of the two complexes. Allowing the complex to optimize fully yielded similar geometries, but the difference increased to $0.24 \mathrm{kcal} / \mathrm{mol}$, which can therefore be attributed mostly to the inclusion of ZPVE. As a result, the magnitude of the binding energy most likely corresponds to that of the partially optimized complex, while the difference corresponds to the fully optimized complex. 
Overall, the interplay between neutral and charged amino acids with the conserved water may be relatively insensitive to the methanol ligand that is present (where the number of hydrogen bonds is equivalent for both structures) but is dependent on the number and type of amino acid side chains. This small energetic difference suggests a situation where the binding equilibrium may be dominated by entropic contributions, which have been shown to be favorable and significant for carbohydrate-lectin binding. $1,35-38,51$

\section{Conclusions}

Binding of HOR to the uncharged linear clusters was either approximately the same as, or not as favorable as, binding to $\left(\mathrm{H}_{2} \mathrm{O}\right)_{2}$, while relative to $\left(\mathrm{H}_{2} \mathrm{O}\right)_{2}$, binding to the charged linear clusters was always favorable. This correlated directly with the consistently more favorable three-body interaction energy in the linear charged clusters. In contrast, the binding of both water and methanol was more favorable for the charged cyclic clusters than for the uncharged cyclic clusters, despite the possible unfavorable three-body term that is mainly due to the charge stabilization over the complex. The binding of either methanol or water to the Con A complex, which contained both neutral and charged amino acid side chains with a total net charge of zero, was found to be similar to that of binding to the water dimer. Overall, the formation of neutral complexes exhibited cooperativity, with the exception of the previously noted asparagine complex, while the exhibition of cooperativity in charged clusters depended on both geometry and presence of charge.

The effect of the corrections to the binding energies was substantial, especially in the case of ZPVE and relaxation. It has been established that the inclusion of ZPVE is necessary to accurately determine the binding energy of hydrogen-bonded water complexes. ${ }^{52}$ In general, the exclusion of ZPVE yielded a binding energy for methanol that was slightly more negative than that for the binding of water. For all trimers, the ZPVE was larger in the case where water was the ligand, relative to methanol, increasing these energetic differences. This is clearly illustrated in the difference obtained between the partially and fully optimized Con A binding energies, where ZPVE was only computed for the fully optimized structure. Relaxation was extremely important in the cases where the AA- $\mathrm{H}_{2} \mathrm{O}$ dimers could form two hydrogen bonds. Also, for the AA- $\mathrm{H}_{2} \mathrm{O}$ dimers investigated here, if it was possible to allow the formation of two hydrogen bonds, the resulting complex was, not surprisingly, energetically more favorable than the complex containing only one hydrogen bond.

The addition of methanol consistently stabilized all of the complexes relative to the addition of a second water molecule. This is in agreement with experimental and theoretical findings that clusters formed with methanol are energetically more favorable than pure water clusters. 53 Therefore, to the extent that methanol served as a model carbohydrate, our results confirmed that water-carbohydrate interactions were generally more favorable than water-water interactions. However, this energetic difference was quite small, reaffirming that entropic contributions are significant in the binding of carbohydrates to proteins.

\section{Supplemental Material}

Refer to Web version on PubMed Central for supplementary material.

\section{Acknowledgements}

We thank the University of Georgia and the National Institutes of Health for financial support (RR05357 and GM55230). In addition, the authors would like to thank Dr. A. Wittkopp and Dr. K. Kirschner for fruitful discussions. 


\section{References}

1. Swaminathan CP, Surolia N, Surolia A. J Am Chem Soc 1998;120:5153-5159.

2. Clarke C, Woods RJ, Gluska J, et al. J Am Chem Soc 2001;123:12238-12247. [PubMed: 11734024]

3. Safo MK, Moure CM, Burnett JC, et al. Protein Sci 2001;10:951-957. [PubMed: 11316875]

4. Brandl M, Meyer M, Suhnel J. J Phys Chem A 2000;104:11177-11187.

5. Loris R, Maes D, Poortmans F, et al. J Biol Chem 1996;271:30614-30618. [PubMed: 8940035]

6. Naismith JH, Field RA. J Biol Chem 1996;271:972-976. [PubMed: 8557713]

7. Viant MR, Cruzan JD, Lucas DD, et al. J Phys Chem A 1997;101:9032-9041.

8. Keutsch FN, Saykally RJ. Proc Natl Acad Sci USA 2001;98:10533-10540. [PubMed: 11535820]

9. Cruzan JD, Viant MR, Brown MG, et al. J Phys Chem A 1997;101:9022-9031.

10. Cruzan JD, Braly LB, Liu K, et al. Science 1996;271:59-62. [PubMed: 11536731]

11. Wales DJ, Walsh RR. J Chem Phys 106;106:7193-7207.

12. Graf S, Leutwyler S. J Chem Phys 1998;109:5393-5403.

13. Xantheas SS, Dunning TH Jr. J Chem Phys 1993;98:8037-8040.

14. Lee HM, Suh SB, Lee JY, et al. J Chem Phys 2000;112:9759-9772.

15. Nielsen IMB, Seidl ET, Janssen CL. J Chem Phys 1999;110:9435-9442.

16. Xantheas SS, Dunning TH Jr. J Chem Phys 1993;99:8774-8792.

17. Klopper W, van Duijneveldt-van de Rijdt JGCM, van Duijneveldt FB. Phys Chem Chem Phys 2000;2:2227-2234.

18. Khan A. J Chem Phys 1997;106:5537-5540.

19. Kirschner KN, Woods RJ. J Phys Chem A 2001;105:4150-4155. [PubMed: 16518456]

20. Peterson KA, Dunning TH Jr. J Chem Phys 1995;102:2032-2041.

21. Gonzalez L, Mo O, Yanez M. J Chem Phys 1998;109:139-150.

22. Mo O, Yanez M, Elguero J. J Chem Phys 1992;97:6628-6638.

23. Xantheas SS, Burnham CJ, Harrison RJ. J Chem Phys 2002;116:1493-1499.

24. Xantheas SS. J Chem Phys 1994;100:7523-7534.

25. Del Bene JE, Jordan MJT. J Mol Struct 2001;573:11-23.

26. Lozynski M, Rusinska-Roszak D, Mack HG. J Phys Chem A 1998;102:2899-2903.

27. Xantheas SS. J Chem Phys 1995;102:4505-4517.

28. Dkhissi A, Ramaekers R, Houben L, et al. Chem Phys Lett 2000;331:553-560.

29. Milet A, Korona T, Moszynski R, et al. J Chem Phys 1999;111:7727-7735.

30. Wang YS, Chang HC, Jiang JC, et al. J Am Chem Soc 1998;120:8777-8788.

31. Del Bene JE, Person WB, Szczepaniak K. J Phys Chem 1995;99:10705-10707.

32. Smith EE, Goldstein IJ. Arch Biochem Biophys 1967;121:88. [PubMed: 6035073]

33. Bradbrook GM, Gleichmann T, Harrop SJ, et al. J Chem Soc, Faraday Trans 1998;94:1603-1611.

34. Naismith JH, Emmerich C, Habash J, et al. Acta Crystallogr D 1994;50:847-858. [PubMed: 15299352]

35. Mandal DK, Kishore N, Brewer CF. Biochemistry 1994;33:1149-1156. [PubMed: 8110746]

36. Bryce RA, Hillier IH, Naismith JH. Biophys J 2001;81:1373-1388. [PubMed: 11509352]

37. Mandal DK, Bhattacharyya L, Koenig SH, et al. Biochemistry 1994;33:1157-1162. [PubMed: 8110747]

38. Schwarz FP, Puri KD, Bhat RG, et al. J Biol Chem 1993;268:7668-7677. [PubMed: 8463297]

39. Soper AK, Finney JL. Phys Rev Lett 1993;71:4346-4349. [PubMed: 10055223]

40. Becke AD. J Chem Phys 1993;98:5648-5652.

41. Lee C, Yang W, Parr RG. Phys Rev B 1988;37:785-789.

42. Frisch, M. J.; Trucks, G. W.; Schlegel, H. B.; et al. Gaussian 98, (Revision A.9); Gaussian, Inc.: Pittsburgh, PA, 1998.

43. Carney JR, Zwier TS. J Phys Chem A 1999;103:9943-9957.

44. Boys SF, Bernardi F. Mol Phys 1970;19:553-566. 
45. Xantheas SS. J Chem Phys 1996;104:8821-8824.

46. Xantheas SS. Chem Phys 2000;258:225-231.

47. Parra RD, Furukawa M, Gong B, et al. J Chem Phys 2001;115:6030-6035.

48. Kim KY, Cho UI, Boo DW. Bull Korean Chem Soc 2001;22:597-604.

49. Chaudhuri C, Wang YS, Jiang JC, et al. Mol Phys 2001;99:1161-1173.

50. Jiang JC, Wang YS, Chang HC, et al. J Am Chem Soc 2000;122:1398-1410.

51. Garcia-Hernandez E, Hernandez-Arana A. Protein Sci 1999;8:1075-1086. [PubMed: 10338018]

52. Scheiner, S. Basis Set Superposition. In Hydrogen bonding a theoretical perspective; Truhlar, D. G., Ed.; Oxford University Press: New York, 1997; pp 23-26.

53. Curtiss LA, Blander M. Chem Rev 1988;88:827-841. 


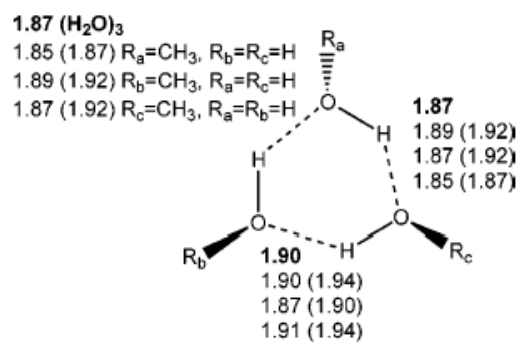

Figure 1.

Hydrogen-bond distances $(\AA)$ in the water trimer (in bold), as well as in three possible $\left(\mathrm{H}_{2} \mathrm{O}\right)_{2}-\mathrm{CH}_{3} \mathrm{OH}$ trimers, at the B3LYP/6-31+G(d) level. The subscripts $\mathrm{a}, \mathrm{b}$, and $\mathrm{c}$ refer to the position of the binding species in the cyclic complex. The values in parentheses were previously obtained at the MP2(full)/6-311+G(d,p) level. ${ }^{21}$ 


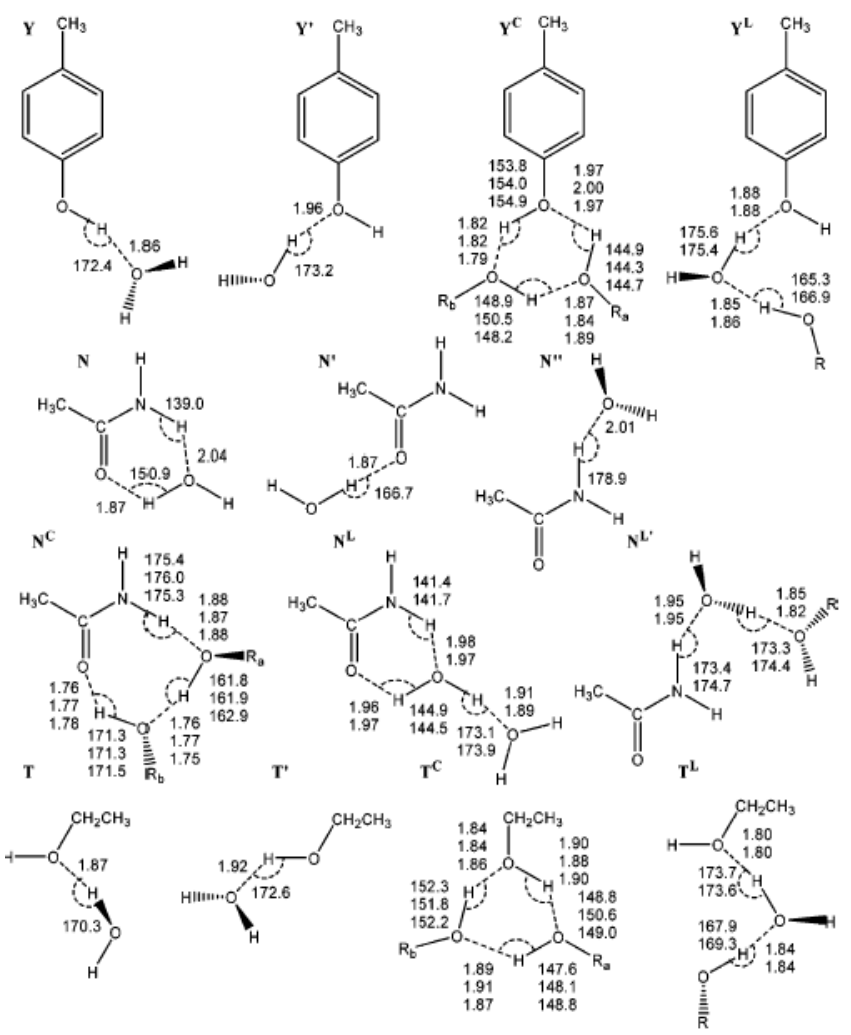

Figure 2.

Geometries for the polar uncharged clusters, where the hydrogen-bond distances are defined top to bottom as $\mathrm{R}_{\mathrm{a}}=\mathrm{R}_{\mathrm{b}}=\mathrm{H}, \mathrm{R}_{\mathrm{a}}=\mathrm{CH}_{3}$ and $\mathrm{R}_{\mathrm{b}}=\mathrm{H}$, and $\mathrm{R}_{\mathrm{a}}=\mathrm{H}$ and $\mathrm{R}_{\mathrm{b}}=\mathrm{CH}_{3}$, and all angles are in degrees. The $\mathbf{N} / \mathbf{Q}$ clusters refer to the representative fragments from either asparagine or glutamine, but will be only be referred to as $\mathbf{N}$ in the text. Likewise, The $\mathbf{S} / \mathbf{T}$ clusters refer to the representative fragments from either serine or threonine, but will only be referred to as $\mathbf{T}$ in the text. 

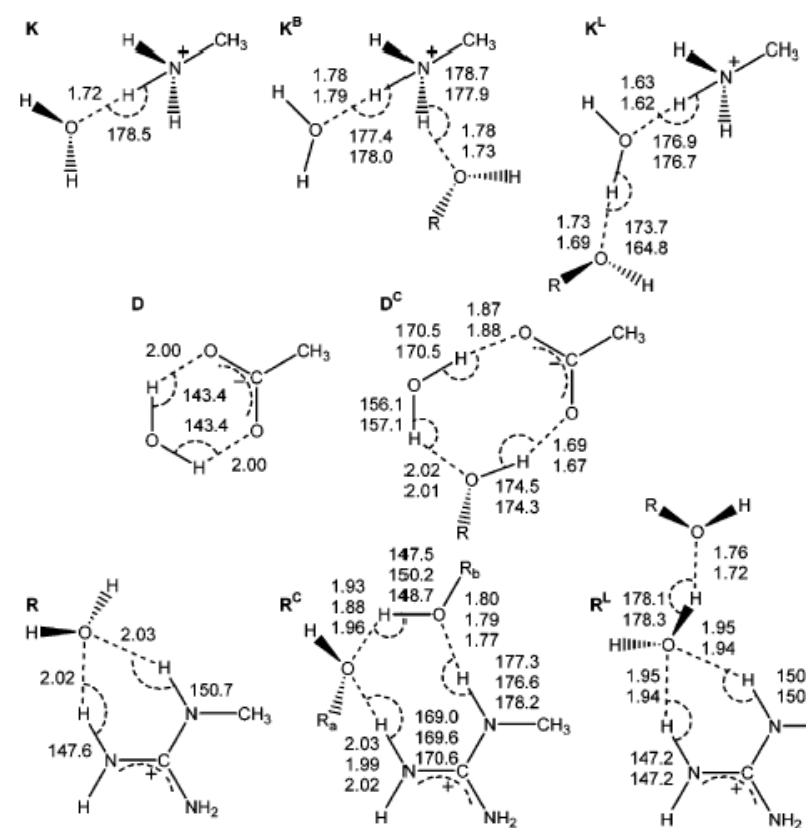

$\begin{array}{ll}\mathrm{D}^{\mathrm{C}} & 1.87 \\ 170.5 & 1.88\end{array}$
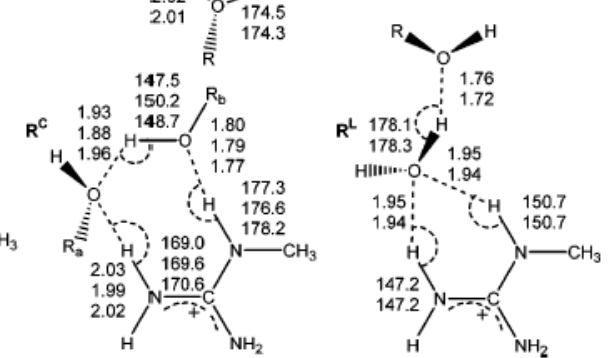

Figure 3.

Geometry of the charged clusters, where the hydrogen-bond distances are defined from top to bottom as $\mathrm{R}_{\mathrm{a}}=\mathrm{R}_{\mathrm{b}}=\mathrm{H}, \mathrm{R}_{\mathrm{a}}=\mathrm{CH}_{3}$ and $\mathrm{R}_{\mathrm{b}}=\mathrm{H}$, and $\mathrm{R}_{\mathrm{a}}=\mathrm{H}$ and $\mathrm{R}_{\mathrm{b}}=\mathrm{CH}_{3}$, and all angles are in degrees. The $\mathrm{D} / \mathrm{E}$ clusters represent the representative fragments from the aspartate and glutamate clusters, but will only be referred to as $\mathrm{D}$ in the text. 


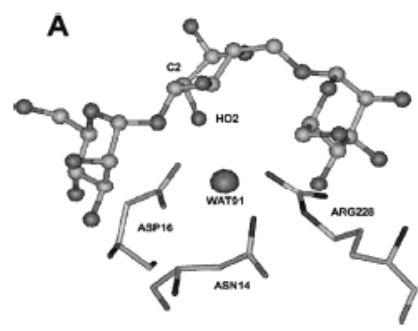

B

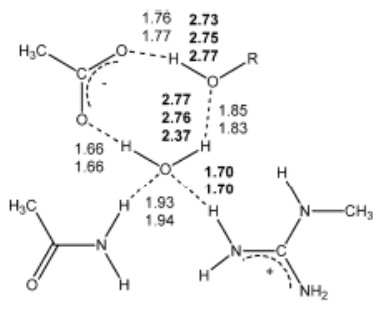

Figure 4.

The cluster representative of the Con A binding site, with the trimannoside in $\mathrm{A}$ and the truncated sugar $\left(\mathrm{R}=\mathrm{CH}_{3}\right)$ in $\mathrm{B}$. The three truncated amino acids shown are asparagine, aspartate, and arginine. The $\mathrm{O} \cdot . \mathrm{O}$ distances are shown in groups of three (in bold), with $\mathrm{R}=\mathrm{H}$, $\mathrm{R}=\mathrm{CH}_{3}$, and the experimental value from top to bottom, respectively, while the $\mathrm{O} \cdot \mathrm{H}$ distances are shown for $\mathrm{R}=\mathrm{H}$ and $\mathrm{R}=\mathrm{CH}_{3}$ from top to bottom, respectively. 
TABLE 1

Binding Energy and Cooperativity Terms ${ }^{a}$

\begin{tabular}{|c|c|c|c|c|c|}
\hline \multirow[b]{2}{*}{ complex } & \multicolumn{2}{|c|}{ binding energy } & \multicolumn{2}{|c|}{ three-body interactionenergy } & \multirow[b]{2}{*}{ hydrogen bonds formed $b$} \\
\hline & $\mathbf{R}=\mathbf{H}$ & $\mathrm{R}=\mathrm{CH}_{3}$ & $\mathbf{R}=\mathbf{H}$ & $\mathrm{R}=\mathrm{CH}_{3}$ & \\
\hline \multicolumn{6}{|l|}{ water } \\
\hline a- & -5.95 & -6.83 & -2.94 & -3.37 & 2 \\
\hline b- & -5.97 & -6.78 & -2.94 & -2.89 & 2 \\
\hline c- & -5.97 & -6.86 & -2.94 & -2.86 & 2 \\
\hline \multicolumn{6}{|l|}{ tyrosine } \\
\hline $\mathbf{Y a}_{\mathrm{R}}^{\mathrm{C}}$ & -5.55 & -6.38 & -2.74 & -2.77 & 2 \\
\hline $\mathbf{Y b}_{\mathbf{R}^{\mathrm{C}}}^{\mathrm{N}}$ & -7.22 & -8.25 & -2.74 & -2.62 & 2 \\
\hline \multirow{2}{*}{\multicolumn{6}{|c|}{ asparagine }} \\
\hline & & & & & \\
\hline $\mathrm{Na}_{\mathrm{R}}^{\mathrm{C}}$ & -8.80 & -9.62 & -4.31 & -4.19 & 2 \\
\hline $\mathrm{Nb}_{\mathrm{R}}^{\mathrm{C}^{\mathrm{n}}}$ & -10.68 & -11.59 & -4.31 & -4.13 & 2 \\
\hline $\mathrm{N}^{\mathrm{L}}$ & -1.61 & -2.30 & 0.14 & 0.13 & 1 \\
\hline $\mathbf{N}^{\mathbf{L} \prime}$ & -3.69 & -4.59 & -1.26 & -1.41 & 1 \\
\hline \multicolumn{6}{|l|}{ threonine } \\
\hline $\mathrm{Ta}^{\mathrm{C}}{ }_{\mathrm{R}}$ & -5.21 & -6.81 & -2.84 & -2.75 & 2 \\
\hline $\mathbf{T b}^{\mathrm{C}_{\mathrm{R}}^{\mathrm{N}}}$ & -7.41 & -7.43 & -2.84 & -2.77 & 2 \\
\hline$T^{L}{ }^{K}$ & -4.28 & -4.92 & -1.92 & -1.88 & 1 \\
\hline \multicolumn{6}{|l|}{ lysine } \\
\hline $\begin{array}{l}\mathbf{K}^{\mathbf{D}} \\
\mathbf{K}^{\mathbf{L}}\end{array}$ & $\begin{array}{l}-13.19 \\
-11.11\end{array}$ & $\begin{array}{l}-15.06 \\
-12.78\end{array}$ & $\begin{array}{r}2.20 \\
-3.76\end{array}$ & $\begin{array}{r}2.83 \\
-4.45\end{array}$ & $\begin{array}{l}1 \\
1\end{array}$ \\
\hline \multirow{2}{*}{\multicolumn{6}{|c|}{$\begin{array}{l}\text { aspartate } \\
\mathbf{D}^{\mathbf{C}}\end{array}$}} \\
\hline & -11.94 & -13.42 & 1.22 & 1.86 & 2 \\
\hline $\begin{array}{l}\underset{\mathbf{R a}_{\mathrm{C}}}{\operatorname{arginine}} \\
\mathbf{R a}_{\mathrm{R}}\end{array}$ & -7.53 & -9.36 & 0.18 & -0.01 & 2 \\
\hline $\mathbf{R b}_{\mathrm{R}}^{\mathrm{C}^{\mathrm{R}}}$ & -7.51 & -8.75 & 0.18 & 0.73 & 2 \\
\hline $\mathbf{R}^{\mathbf{L}}$ & -9.64 & -11.00 & -3.71 & -4.41 & 1 \\
\hline $\operatorname{Con} \mathrm{A}^{c}$ & -12.83 & -12.85 & -1.13 & -0.75 & 2 \\
\hline Con $\mathrm{A}^{d}$ & -5.70 & -5.94 & -0.84 & -0.65 & 2 \\
\hline
\end{tabular}

${ }^{a}$ All energies are in $\mathrm{kcal} / \mathrm{mol}$; positive values represent repulsive terms.

${ }^{b}$ Number of hydrogen bonds formed involving the binding moiety.

${ }^{c}$ Partially optimized complex.

$d_{\text {Fully optimized complex. }}$ 
TABLE 2

Energy Difference between the Low Energy Neutral AA-(Conserved Water) Clusters

\begin{tabular}{llc}
\hline complex & energy $^{\boldsymbol{a}}$ & $\Delta \boldsymbol{E}^{\boldsymbol{b}}$ \\
\hline $\mathbf{T}$ & -231.579570 & 0.00 \\
$\mathbf{T}^{\prime}$ & -231.578074 & 0.94 \\
$\mathbf{Y}$ & -423.385781 & 0.00 \\
$\mathbf{Y}^{\prime}$ & -423.382359 & 2.15 \\
$\mathbf{N}^{\prime}$ & -285.782341 & 0.00 \\
$\mathbf{N}^{\prime \prime}$ & -285.778791 & 2.23 \\
$\mathbf{N}^{\prime \prime}$ & -285.774871 & 4.69 \\
\hline${ }_{\text {Hartrees. }}$ & & \\
$b_{\text {kcal/mol. }}$ & &
\end{tabular}


TABLE 3

Energy Comparison between Low Energy AA-(conserved water)-HOR $\left(\mathrm{R}=\mathrm{H}, \mathrm{CH}_{3}\right)$ Clusters

\begin{tabular}{|c|c|c|c|c|c|}
\hline complex & energy $^{a}$ & $\Delta E^{b}$ & cluster & energy $^{a}$ & $\Delta E^{b}$ \\
\hline $\mathbf{Y}_{R=H}^{C}$ & -499.864594 & 0.00 & $\mathbf{Y}_{\mathrm{R}_{\mathrm{g}}=\mathrm{CH}_{3}}^{\mathrm{C}}$ & -539.174669 & 0.00 \\
\hline $\mathbf{Y}_{\mathrm{R}=\mathrm{H}}^{\mathrm{L}}$ & -499.857603 & 4.39 & $\begin{array}{l}\mathbf{Y}_{\mathrm{R}_{\mathrm{b}}=\mathrm{CH}_{3}}^{\mathrm{C}_{3}} \\
\mathbf{Y}_{\mathbf{R}=\mathrm{CH}_{3}}^{\mathrm{L}_{3}}\end{array}$ & $\begin{array}{l}-539.174657 \\
-539.167162\end{array}$ & $\begin{array}{l}0.01 \\
4.71\end{array}$ \\
\hline $\mathbf{N}_{\mathbf{R}=\mathbf{H}}^{\mathrm{C}}$ & -362.263666 & 0.00 & $\mathbf{N}_{\mathbf{R}_{\mathrm{a}}=\mathrm{CH}_{3}}^{\mathrm{C}}$ & -401.573377 & 0.16 \\
\hline $\mathbf{N}_{\mathbf{R}=\mathbf{H}}^{\mathbf{L}=\mathbf{H}}$ & -362.252544 & 6.98 & $\mathrm{~N}_{\mathrm{R}_{\mathrm{b}}=\mathrm{CH}_{3}}^{\mathrm{C}^{\mathrm{K}_{\mathrm{a}}=\mathrm{H}_{3}}}$ & -401.573635 & 0.00 \\
\hline $\mathbf{N}^{\mathbf{L}{ }^{N-11}=\mathbf{H}}$ & -362.24968 & 8.78 & & $\begin{array}{l}-401.562891 \\
-401.560236\end{array}$ & $\begin{array}{l}6.74 \\
8.41\end{array}$ \\
\hline$T_{R=H}^{C}$ & -308.059153 & 0.00 & $\mathbf{T}_{\mathrm{R}_{\mathrm{g}}=\mathrm{CH}_{3}}^{\mathrm{C}}$ & -347.369102 & 0.00 \\
\hline$T_{R=H}^{L}$ & -308.055461 & 2.32 & & $\begin{array}{l}-347.369029 \\
-347.365001\end{array}$ & $\begin{array}{l}0.05 \\
2.57\end{array}$ \\
\hline $\mathbf{K}_{\mathbf{R}=\mathbf{H}}^{\mathrm{B}}$ & -249.237748 & 0.00 & $\mathbf{K}_{\mathrm{R}=\mathrm{CH}_{3}}^{\mathrm{B}=\mathrm{CH}_{3}}$ & -288.549756 & 0.00 \\
\hline $\mathbf{K}_{\mathbf{R}=\mathbf{H}}^{\mathbf{L}}$ & -249.235109 & 1.66 & $\mathbf{K}_{\mathrm{R}=\mathrm{CH}_{3}}^{\mathrm{L}}$ & -288.546821 & 1.84 \\
\hline$D_{R=H}^{C}$ & -381.59955 & 0.00 & $D_{D_{R}}^{C^{C}}$ & -420.910217 & 0.00 \\
\hline $\mathbf{R}_{\mathrm{R}=\mathrm{H}}^{\mathrm{C}}$ & -398.145732 & 1.82 & $\mathbf{R}_{\mathbf{R}_{3}=\mathrm{CH}_{3}}^{\mathrm{C}}$ & -437.457414 & 1.62 \\
\hline $\mathbf{R}_{\mathrm{R}=\mathrm{H}}^{\mathrm{L}}$ & -398.148638 & 0.00 & $\begin{array}{c}\mathbf{R}_{\mathbf{R}_{\mathrm{b}}=\mathrm{CH}_{3}}^{\mathrm{C}_{3}} \\
\mathbf{R}_{\mathbf{R}=\mathrm{CH}_{3}}^{\mathrm{L}_{3}}\end{array}$ & $\begin{array}{l}-437.456554 \\
-437.459989\end{array}$ & $\begin{array}{l}2.16 \\
0.00\end{array}$ \\
\hline
\end{tabular}

${ }^{a}$ Hartrees.

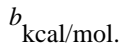

